\title{
Transverse shrinkage variations within tree stems of Melia azedarach planted in northern Vietnam
}

\author{
Doan Van Duong ${ }^{1,2} \cdot$ Junji Matsumura ${ }^{3}$
}

Received: 13 April 2018 / Accepted: 12 August 2018 / Published online: 31 August 2018

(C) The Japan Wood Research Society 2018

\begin{abstract}
This study quantified variations within tree stems in tangential shrinkage $\left(\alpha_{\mathrm{T}}\right)$, radial shrinkage $\left(\alpha_{\mathrm{R}}\right)$, and tangential/radial shrinkage ratio $\left(\alpha_{\mathrm{T}} / \alpha_{\mathrm{R}}\right)$ of Melia azedarach grown in two different sites in northern Vietnam. The overall values of $\alpha_{\mathrm{T}}, \alpha_{\mathrm{R}}$, and $\alpha_{\mathrm{T}} / \alpha_{\mathrm{R}}$ were $7.05 \%, 4.38 \%$, and 1.64, respectively. The variation pattern in $\alpha_{\mathrm{T}}$ and $\alpha_{\mathrm{R}}$ was found to increase gradually from pith to bark and this trend was similar on both sites. In radial direction, the $\alpha_{\mathrm{T}} / \alpha_{\mathrm{R}}$ decreased significantly from 10 to $50 \%$ of the radial length from pith before approaching a constant value toward the outside. The transverse shrinkage variation with height was very small and without statistical significance. There were strong positive relationships between transverse shrinkage and basic density (BD). This implies that the selection for high wood density may lead to increase wood transverse shrinkage. In addition, the $\alpha_{\mathrm{T}}$ and $\alpha_{\mathrm{R}}$ had significant positive linear relationships with both acoustic wave velocity $\left(V_{\mathrm{L}}\right)$ and dynamic modulus of elasticity of $\log \left(\mathrm{DMOE}_{\text {log }}\right)$. This result suggests that it might be possible to sort lumber with large transverse shrinkage by stress wave method for M. azedarach planted in northern Vietnam.
\end{abstract}

Keywords Melia azedarach $\cdot$ Transverse shrinkage $\cdot$ Non-destructive evaluation $\cdot$ Radial position

\section{Introduction}

Wood is a highly variable material due to its biological origin [1]. For a given species, the within-tree variation is further partitioned into variation from pith to bark (radial variation) and variation with position along the stem (axial variation). The large variability of wood characteristics makes it difficult to precisely predict its performance and, therefore, to efficiently process and utilize the material. On the other hand, the variability means that this material has potential for genetic improvement and diverse end uses [2]. Therefore, a better understanding of the wood variability

Junji Matsumura

matumura@agr.kyushu-u.ac.jp

1 Graduate School of Bioresource and Bioenvironmental Sciences, Kyushu University, 744 Motooka, Nishi-ku, Fukuoka 819-0395, Japan

2 Faculty of Forestry, Thai Nguyen University of Agriculture and Forestry, Thai Nguyen, Vietnam

3 Laboratory of Wood Science, Faculty of Agriculture, Kyushu University, 744 Motooka, Nishi-ku, Fukuoka 819-0395, Japan within a tree is of value to both wood quality improvement and efficient wood processing and utilization.

Dimensional stability and warp are major concerns in wood drying, processing, and utilization. This problem is believed to be caused by gradients of wood anisotropic shrinkage both in radial and tangential directions [3]. Shrinkage is a physical property of wood that significantly affects its usability in products. Small shrinkage values are an advantage in use for some wood species. Volume change is not equal in all directions. Tangentially, wood shrinks from 6 to $12 \%$ of the green dimension when dried from green to oven-dry condition for hardwood [4]; while in the radial direction, the corresponding shrinkage is roughly onehalf of the tangential shrinkage for a given wood specimen. This differential radial-tangential shrinkage is one of the primary factors causing shape distortion during seasoning of lumber and during ultimate use [5].

The most important factor affecting shrinkage is wood density, because wood shrinks by an amount that is proportional to the moisture lost from the cell wall [6]. Thus, it is important to know the relationship between transverse shrinkage and density. Besides, if the lumber was sorted by shrinkage properties, it is expected that the drying yield would increase and the cost and energy consumption would 
decrease. A number of studies also suggested that acoustic wave techniques may be used to assess the dimensional stability of structural lumber [5, 7-10]. Yamashita et al. [7, 8] showed that there were close relationships between longitudinal-transversal shrinkage and modulus of elasticity of logs measured by tapping the logs in the green condition in Sugi (Cryptomeria japonica). Wang and Simpson [9] found the potential of acoustic analysis as presorting criteria to identify warp-prone boards before kiln-drying in Ponderosa pine (Pinus ponderosa). The results showed a statistically significant correlation between acoustic properties of the boards and the grade loss because of exceeding warp limits. In addition, Dundar et al. [5, 10] indicated that ultrasonic measurement in green condition has a good potential for predicting the transverse shrinkages both in hardwood and softwood species.

Melia azedarach, a deciduous tree belonging to the family of Meliaceae, is native to the Himalaya region of Asia [11]. The species is well adapted to warm climates, poor soils, and seasonally dry conditions [12]. It is now naturalized in most subtropical and tropical regions of the world [13]. In Vietnam, M. azedarach is planted popularly in most of the provinces in northern. The decrease in the available wood resources and the increase in wood processing costs have led to a significant interest in wood from plantation. In furniture industry, wood of M. azedarach has received recently considerable attention given its relatively fine grains, quite durable, resistant to termites and insects, and easy to work [14]. However, there is little information regarding to assess its dimensional stability, especially about the transverse shrinkage variations within tree including radial and axial variations.

The main objective of this study was, therefore, to investigate within-tree variation in transverse shrinkage properties in $M$. azedarach planted at two different sites in northern Vietnam. The specific objectives were to: (1) investigate radial and axial patterns of wood transverse shrinkage from pith to bark at different stem heights within trees, (2) determine the relationship between transverse shrinkage and basic density (BD), and (3) determine the non-destructive parameters for predicting transverse shrinkage in terms of sorting lumber with high transverse shrinkage. Besides, the quality of timber produced from M. azedarach in Vietnam was assessed based on their physical properties for grading purpose.

\section{Materials and methods}

\section{Sampling}

The sample trees for this study were collected from stateowned plantations in two different sites: Tuyen Quang
Table 1 General characteristics of the study sites [15]

\begin{tabular}{lll}
\hline Description & Site 1 Northeast & Site 2 Northwest \\
\hline Province & Tuyen Quang & Son La \\
Latitude & $22^{\circ} 17^{\prime} 01^{\prime \prime} \mathrm{N}$ & $20^{\circ} 56^{\prime} 18^{\prime \prime} \mathrm{N}$ \\
Longitude & $105^{\circ} 19^{\prime} 22^{\prime \prime} \mathrm{E}$ & $104^{\circ} 26^{\prime} 25^{\prime \prime} \mathrm{E}$ \\
Altitude $(\mathrm{m})$ & 112 & 434 \\
Mean rainfall $\left(\mathrm{mm} \mathrm{year}^{-1}\right)$ & 2000 & 1300 \\
Mean temperature $\left({ }^{\circ} \mathrm{C}\right)$ & 23.4 & 24.0 \\
Soil origin & Calcisols & Ferralsols \\
\hline
\end{tabular}

Table 2 Age, diameter at breast height, and total stem height of sampled Melia azedarach trees [15]

\begin{tabular}{lllll}
\hline Site & Tree no. & Age $^{\text {a }}$ (years) & DBH $(\mathrm{cm})$ & $H(\mathrm{~m})$ \\
\hline Site 1 & 1 & 18 & 32.5 & 19.6 \\
& 2 & 19 & 32.2 & 21.1 \\
& 3 & 17 & 32.5 & 21.4 \\
Site 2 & 4 & 18 & 33.8 & 20.1 \\
& 5 & 18 & 32.2 & 19.1 \\
& 6 & 17 & 29.9 & 21.4 \\
\hline
\end{tabular}

$D B H$ diameter at breast height (at $1.3 \mathrm{~m}$ above the ground), $H$ tree height

${ }^{\text {a }}$ Measured by ring counting at the $15 \mathrm{~cm}$ above the ground

province (Northeast) and Son La province (Northwest) in northern Vietnam (Table 1). A total of six trees around 17-19 years old (the number of growth ring was counted at $15 \mathrm{~cm}$ above the ground and considered as the approximate age of tree) was chosen basing on straight trunks, normal branching, and no signs of any diseases or pest symptoms. The trees were planted at a stand density of 830 trees per hectare at spacing of $4 \mathrm{~m} \times 3 \mathrm{~m}$ from seedlings produced by seeds from natural forests located near each site. The trees were felled through cutting their stems at $15 \mathrm{~cm}$ above the soil level. From each tree, $50-\mathrm{cm}-\operatorname{long} \operatorname{logs}$ were taken at different height levels $(0.3,1.3,3.3,5.3$, and $7.3 \mathrm{~m}$ heights from above the ground). The north and south sides of each tree were marked before felling. Sample trees were the same as those used in the previous study on variation in intrinsic wood properties (Table 2) [15].

\section{Dynamic modulus of elasticity of $\log \left(\mathrm{DMOE}_{\mathrm{log}}\right)$}

$\mathrm{DMOE}_{\text {log }}$ was measured by stress wave method in the green condition for each log. The Fakopp (Fakopp microsecond timer made in Hungary) device measures the time of acoustic wave propagation through axial log. This equipment consists of two electrodes nailed into the middle positions from pith to bark on each side of log (Fig. 1). The acoustic signal is created by a hammer strike on the start transducer. The 


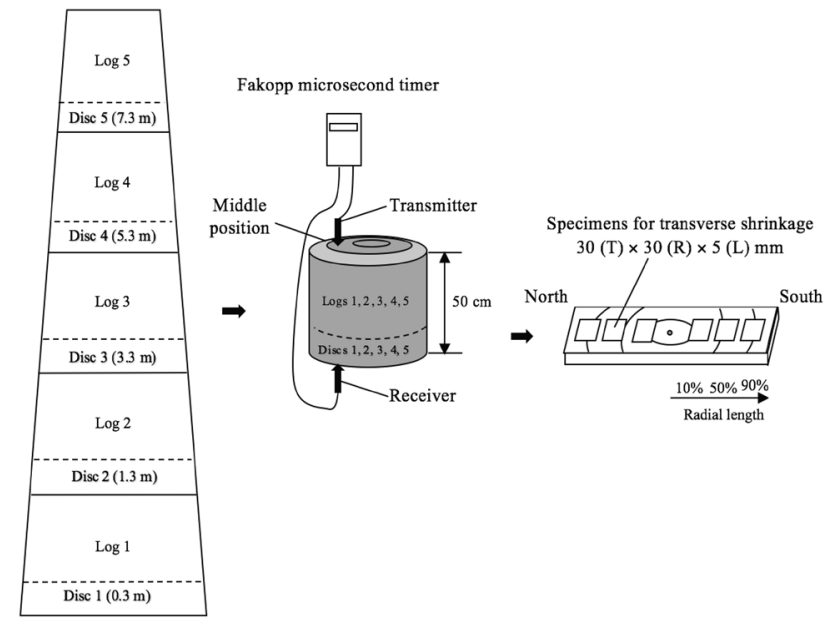

Fig. 1 Method of measuring dynamic modulus of elasticity of $\log$ $\left(\mathrm{DMOE}_{\mathrm{log}}\right)$ and cutting specimens from each tree

propagation time measurement was repeated five times for each $\log$, and an average value was used as the experimental value. The velocity of acoustic wave propagation is a ratio of length of log per propagation time. The green density of logs was immediately measured as green weight per green volume. $\mathrm{DMOE}_{\log }$ in the direction parallel to grain was then determined by a simple relation:

$\mathrm{DMOE}_{\log }=\rho \cdot V_{\mathrm{L}}^{2}$,

where $\mathrm{DMOE}_{\text {log }}$ dynamic modulus of elasticity of $\log (\mathrm{GPa})$, $\rho$ green density of $\log \left(\mathrm{kg} / \mathrm{m}^{3}\right)$, and $V_{\mathrm{L}}$ acoustic wave velocity $(\mathrm{m} / \mathrm{s})$.

\section{BD and transverse shrinkage}

From above logs, a disk of $3 \mathrm{~cm}$ thickness was cut to measure transverse shrinkage and BD in each log. Tangential shrinkage $\left(\alpha_{\mathrm{T}}\right)$, radial shrinkage $\left(\alpha_{\mathrm{R}}\right)$, and $\mathrm{BD}$ were measured using Japanese Industrial Standards (JIS Z2101) [16] at different radial and height positions. The specimens with dimensions of $30 \times 30 \times 5 \mathrm{~mm}$ (tangential $\times$ radial $\times$ longitudinal) were taken at 10,50 , and $90 \%$ of the radial length from pith on both sides (north and south) at different heights $(0.3,1.3,3.3$, 5.3, and $7.3 \mathrm{~m}$ heights above the ground) (Fig. 1). The total number of small clear wood specimens was 180 . After the dimensions were measured in green wood, the samples were conditioned in a room at a constant temperature $\left(20^{\circ} \mathrm{C}\right)$ and relative humidity $(60 \%)$ to constant weight to minimize negative influence of drying stress on the shrinkage. The samples were then oven-dried for one night at $60^{\circ} \mathrm{C}$ and for two nights at $103{ }^{\circ} \mathrm{C}$ to determine the oven-dry weight and dimensions. A centerline parallel to the radial direction and one parallel to the tangential direction were drawn on the surface of each
Table 3 Model used in the analysis of variance

\begin{tabular}{ll}
\hline No. & Source of variation \\
\hline 1 & Site $(\mathrm{S})$ \\
2 & Height level (L) \\
3 & $\mathrm{~L} \times \mathrm{S}$ \\
4 & Radial position (P) \\
5 & $\mathrm{P} \times \mathrm{S}$ \\
6 & $\mathrm{P} \times \mathrm{L}$ \\
7 & $\mathrm{P} \times \mathrm{L} \times \mathrm{S}$ \\
8 & Residuals \\
\hline
\end{tabular}

specimen for the length measurement. The dimensions in radial and tangential directions of specimens were measured in the green and oven-dried conditions using a Mitutoyo digital micrometer CD-S20C (minimum scale: $0.01 \mathrm{~mm}$ ). The tangential/radial shrinkage ratio $\left(\alpha_{\mathrm{T}} / \alpha_{\mathrm{R}}\right)$ was obtained as $\alpha_{\mathrm{T}}$ divide by $\alpha_{\mathrm{R}}$. BD was obtained as oven-dry weight per green volume. Shrinkage was calculated as following:

$\alpha=\frac{l_{\mathrm{g}}-l_{\mathrm{o}}}{l_{\mathrm{g}}} \times 100$,

where $l_{\mathrm{g}}$ length of centerline which was measured at green condition $(\mathrm{mm}), l_{\mathrm{o}}$ length of centerline which was measured at oven-dry condition (mm), and $\alpha$ shrinkage from green to oven-dry (\%).

\section{Data analysis}

Analysis of variance (ANOVA) for all wood shrinkage properties $\left(\alpha_{\mathrm{T}}, \alpha_{\mathrm{R}}\right.$, and $\left.\alpha_{\mathrm{T}} / \alpha_{\mathrm{R}}\right)$ was performed according to the mixed model where stem height and radial direction were considered as fixed effects and site was considered as random effect (Table 3). Variance components for the sources of variation were also estimated. Besides, the differences among radial and height positions within stem were examined by Tukey-Kramer HSD test. All statistical analyses were performed using R software version 3.2.3 [17].

\section{Grade yield}

Grade yield for the specimens was checked using the grading standard of physical properties of timbers from Southeast Asia and Pacific regions by Forestry and Forest Products Research Institute (FFPRI) in Japan (Table 4) [18]. 
Table 4 Grading standard of physical properties of timber from Southeast Asia and Pacific regions by Forestry and Forest Products Research Institute (1975) [18]

\begin{tabular}{|c|c|c|}
\hline \multirow[t]{2}{*}{ Grade } & \multicolumn{2}{|c|}{ Shrinkage from green to oven dry } \\
\hline & Tangential (\%) & Radial (\%) \\
\hline I & $\leq 6.2$ & $\leq 2.6$ \\
\hline II & $6.3-8.0$ & $2.7-3.8$ \\
\hline III & $8.1-9.8$ & $3.9-5.0$ \\
\hline IV & $9.9-11.6$ & $5.1-6.1$ \\
\hline V & $\geq 11.7$ & $\geq 6.2$ \\
\hline
\end{tabular}

\section{Results and discussion}

\section{BD and transverse shrinkage}

Table 5 summarizes the statistics of BD and transverse shrinkage from green to oven-dry condition for $M$. azedarach planted in northern Vietnam. The overall values of BD, $\alpha_{\mathrm{T}}, \alpha_{\mathrm{R}}$, and $\alpha_{\mathrm{T}} / \alpha_{\mathrm{R}}$ in the six trees averaged over the stem heights are $0.43 \mathrm{~g} / \mathrm{cm}^{3}, 7.05 \%, 4.38 \%$, and 1.64 , respectively. Values for the equivalent properties reported by Pramana [19], Venson et al. [20], Botero [21], and Coronel [22] for M. azedarach trees grown in different countries are given in Table 6 for comparison.

Variation along the radial direction is the best known and most studied within-tree variability in wood, which is generally reflected as radial pattern of change in wood characteristics. Table 7 shows that radial position had a significant effect on shrinkage $(p<0.001)$ and contributed the highest to the total variation in $\alpha_{\mathrm{T}}(42.38 \%)$ and $\alpha_{\mathrm{R}}(45.54 \%)$. The pattern and magnitude of variation on shrinkage in radial direction from pith to bark are shown
Table 6 Shrinkage parameter of Melia azedarach planted in northern Vietnam compared with corresponding data of Melia azedarach planted from other provenances

\begin{tabular}{llll}
\hline Source & $\begin{array}{l}\text { Shrinkage from } \\
\text { green to oven dry } \\
\\
\alpha_{\mathrm{T}}(\%)\end{array}$ & $\alpha_{\mathrm{R}}(\%)$ & $\alpha_{\mathrm{T}} / \alpha_{\mathrm{R}}$ \\
\hline This study (17-19) & $6.73-7.37$ & $4.10-4.67$ & $1.68-1.60$ \\
Indonesia $^{\mathrm{a}}(19)$ & 7.50 & 4.40 & 1.70 \\
Mexico $^{\mathrm{b}}(11)$ & 7.90 & 4.10 & 1.90 \\
Brazil $^{\mathrm{c}}$ & $5.70-8.60$ & $2.30-5.70$ & $2.50-1.50$ \\
Argentina $^{\mathrm{d}}$ & 9.80 & 4.50 & 2.20 \\
\hline
\end{tabular}

Age of tree was given in parentheses

${ }^{\text {a }}$ Pramana [19]

${ }^{\mathrm{b}}$ Venson et al. [20]

${ }^{\mathrm{c}}$ Botero [21]

${ }^{\mathrm{d}}$ Coronel [22]

in Fig. 2. While $\alpha_{\mathrm{T}}$ and $\alpha_{\mathrm{R}}$ increased from pith to bark, $\alpha_{\mathrm{T}} / \alpha_{\mathrm{R}}$ decreased from pith outwards. The radial variation pattern of transverse shrinkage is maintained at the different height levels of the tree $(\mathrm{P} \times \mathrm{L}$ : no significant $)$ and similar between two sites $(\mathrm{P} \times \mathrm{S}$ : no significant) (Table 7). The opposite trends of $\alpha_{\mathrm{R}}$ and $\alpha_{\mathrm{T}} / \alpha_{\mathrm{R}}$ might have occurred because the within-tree variation of $\alpha_{\mathrm{R}}$ was larger than that of $\alpha_{\mathrm{T}}$. The present results are in line with those of other researchers $[23,24]$ who reported that transverse shrinkage increased from pith outwards in Cedrela odorata and Populus euramericana, respectively. However, there were different reports about the variation of transverse shrinkage from pith to bark in other hardwood species. Anoop et al. [25] reported that along the radial positions, there was no significant difference of transverse shrinkage in Swietenia macrophylla. Shanavas and Kumar [26] showed that the
Table 5 Variation in basic density (BD), tangential shrinkage $\left(\alpha_{\mathrm{T}}\right)$, radial shrinkage $\left(\alpha_{\mathrm{R}}\right)$, and tangential/radial shrinkage ratio $\left(\alpha_{\mathrm{T}} / \alpha_{\mathrm{R}}\right)$ within stem and between sites of Melia azedarach

\begin{tabular}{lllllll}
\hline Variable & Description & $n$ & $\mathrm{BD}\left(\mathrm{g} / \mathrm{cm}^{3}\right)$ & $\alpha_{\mathrm{T}}(\%)$ & $\alpha_{\mathrm{R}}(\%)$ & $\alpha_{\mathrm{T}} / \alpha_{\mathrm{R}}$ \\
\hline Radial position from pith (\%) & 10 & 60 & $0.39 \pm 0.001^{\mathrm{c}}$ & $6.34 \pm 0.07^{\mathrm{c}}$ & $3.69 \pm 0.09^{\mathrm{c}}$ & $1.76 \pm 0.03^{\mathrm{a}}$ \\
& 50 & 60 & $0.44 \pm 0.001^{\mathrm{b}}$ & $7.22 \pm 0.09^{\mathrm{b}}$ & $4.56 \pm 0.06^{\mathrm{b}}$ & $1.59 \pm 0.02^{\mathrm{b}}$ \\
& 90 & 60 & $0.47 \pm 0.001^{\mathrm{a}}$ & $7.61 \pm 0.08^{\mathrm{a}}$ & $4.90 \pm 0.07^{\mathrm{a}}$ & $1.56 \pm 0.02^{\mathrm{b}}$ \\
Height above the ground (m) & 0.3 & 36 & $0.45 \pm 0.01^{\mathrm{a}}$ & $7.30 \pm 0.12^{\mathrm{a}}$ & $4.52 \pm 0.13^{\mathrm{a}}$ & $1.65 \pm 0.04^{\mathrm{a}}$ \\
& 1.3 & 36 & $0.43 \pm 0.01^{\mathrm{a}}$ & $7.14 \pm 0.12^{\mathrm{a}}$ & $4.32 \pm 0.14^{\mathrm{a}}$ & $1.69 \pm 0.04^{\mathrm{a}}$ \\
& 3.3 & 36 & $0.43 \pm 0.01^{\mathrm{a}}$ & $7.03 \pm 0.15^{\mathrm{a}}$ & $4.28 \pm 0.13^{\mathrm{a}}$ & $1.67 \pm 0.03^{\mathrm{a}}$ \\
& 5.3 & 36 & $0.42 \pm 0.01^{\mathrm{a}}$ & $6.87 \pm 0.14^{\mathrm{a}}$ & $4.38 \pm 0.13^{\mathrm{a}}$ & $1.59 \pm 0.03^{\mathrm{a}}$ \\
& 7.3 & 36 & $0.44 \pm 0.01^{\mathrm{a}}$ & $6.93 \pm 0.14^{\mathrm{a}}$ & $4.41 \pm 0.11^{\mathrm{a}}$ & $1.58 \pm 0.03^{\mathrm{a}}$ \\
Site & 1 & 90 & $0.42 \pm 0.01^{\mathrm{b}}$ & $6.73 \pm 0.08^{\mathrm{b}}$ & $4.10 \pm 0.08^{\mathrm{b}}$ & $1.68 \pm 0.02^{\mathrm{a}}$ \\
& 2 & 90 & $0.44 \pm 0.01^{\mathrm{a}}$ & $7.37 \pm 0.08^{\mathrm{a}}$ & $4.67 \pm 0.07^{\mathrm{a}}$ & $1.60 \pm 0.02^{\mathrm{b}}$ \\
Mean & & 180 & $0.43 \pm 0.01$ & $7.05 \pm 0.06$ & $4.38 \pm 0.06$ & $1.64 \pm 0.02$ \\
\hline
\end{tabular}

Mean values are followed by standard errors $n$ number of wood specimen

${ }^{a, b, c}$ Means with different superscript within a column significantly differ $(p<0.05)$ 
Table 7 Variance components for tangential shrinkage $\left(\alpha_{\mathrm{T}}\right)$, radial shrinkage $\left(\alpha_{\mathrm{R}}\right)$, and tangential/radial shrinkage ratio $\left(\alpha_{\mathrm{T}} / \alpha_{\mathrm{R}}\right)$ of Melia azedarach

\begin{tabular}{|c|c|c|c|c|c|c|c|}
\hline \multirow[t]{2}{*}{ Source of variation } & \multirow[t]{2}{*}{$d f$} & \multicolumn{2}{|l|}{$\alpha_{\mathrm{T}}$} & \multicolumn{2}{|l|}{$\alpha_{\mathrm{R}}$} & \multicolumn{2}{|l|}{$\alpha_{\mathrm{T}} / \alpha_{\mathrm{R}}$} \\
\hline & & $p$ value & Var\% & $p$ value & Var\% & $p$ value & $\operatorname{Var} \%$ \\
\hline Site (S) & 1 & 0.001 & 15.39 & 0.001 & 13.93 & 0.017 & 3.17 \\
\hline Height level (L) & 4 & 0.163 & 3.64 & 0.712 & 1.20 & 0.092 & 4.43 \\
\hline $\mathrm{L} \times \mathrm{S}$ & 4 & 0.087 & 3.91 & 0.888 & 0.59 & 0.069 & 4.55 \\
\hline Radial position $(\mathrm{P})$ & 2 & 0.001 & 42.38 & 0.001 & 45.54 & 0.001 & 16.27 \\
\hline $\mathrm{P} \times \mathrm{S}$ & 2 & 0.289 & 0.57 & 0.229 & 0.70 & 0.209 & 1.38 \\
\hline $\mathrm{P} \times \mathrm{L}$ & 8 & 0.863 & 0.89 & 0.957 & 0.61 & 0.552 & 3.00 \\
\hline $\mathrm{P} \times \mathrm{L} \times \mathrm{S}$ & 8 & 0.508 & 1.55 & 0.375 & 2.05 & 0.858 & 1.73 \\
\hline Residuals & 150 & & 31.67 & & 35.38 & & 65.47 \\
\hline
\end{tabular}

$d f$ degrees of freedom, Var variance (\%)

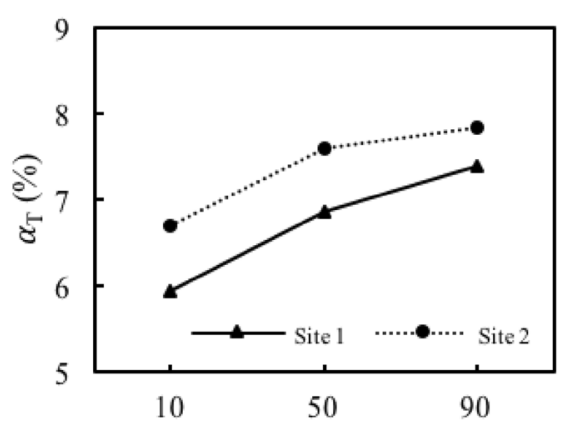

Radial position from pith (\%)

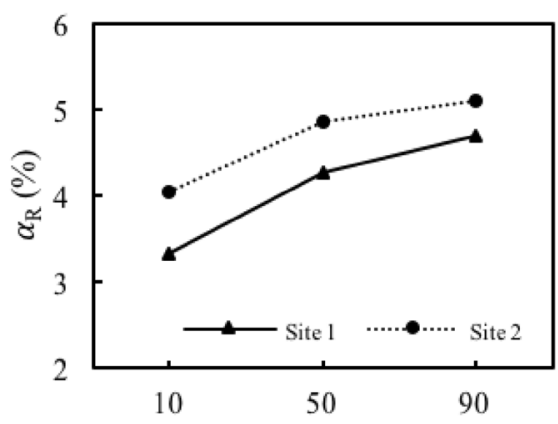

Radial position from pith (\%)

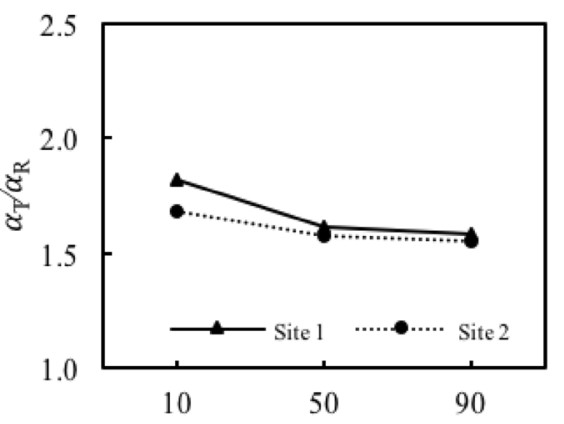

Radial position from pith (\%)

Fig. 2 Radial variation in tangential shrinkage $\left(\alpha_{\mathrm{T}}\right)$, radial shrinkage $\left(\alpha_{\mathrm{R}}\right)$, and tangential/radial shrinkage ratio $\left(\alpha_{\mathrm{T}} / \alpha_{\mathrm{R}}\right)$ for two different sites of Melia azedarach

trend for $\alpha_{\mathrm{T}}$ and $\alpha_{\mathrm{R}}$ decreased from pith towards periphery in Acacia mangium, the reverse trend was true with Acacia auriculiformis and Grevillea robusta exhibited the highest $\alpha_{\mathrm{T}}$ and $\alpha_{\mathrm{R}}$ values for the outer position. Based on the present results and previous reports on other hardwood species, the within-tree trend of transverse shrinkage along radial direction might be different by species. This is due to the differences in wood density, microfibril angle (MFA) in the $S_{2}$ layer of cell walls, and anatomical structures among wood species. In the next section, we focus on relationship between transverse shrinkage and BD to examine the effect of BD on $\alpha_{\mathrm{T}}$ and $\alpha_{\mathrm{R}}$.

MFA is known to have a large and direct effect on shrinkages. The angle between the direction of microfibrils and the longitudinal axis is called the MFA. Because crystalline cellulose is strong, stiff, and does not absorb moisture, the wood shrinks very little in the direction that is parallel to cellulose microfibrils. Therefore, transverse shrinkage increases and longitudinal shrinkage decreases with the decrease of MFA. In the previous study [15], we found that MFA of $M$. azedarach followed a declining trend from near the pith $\left(16^{\circ}\right)$ to bark $\left(12^{\circ}\right)$ (measured at only $1.3 \mathrm{~m}$ heigh above the ground) which was the opposite trend of transverse shrinkages $\left(\alpha_{\mathrm{T}}\right.$ and $\left.\alpha_{\mathrm{R}}\right)$ observed in this study. Hence, the within-tree variation in MFA together with density could explain to be larger of transverse shrinkage in the outer wood than in the inner wood presented in this study. Besides, earlywood-latewood proportion observed by a pore zone (earlywood) containing larger vessels, fewer fibers, and thinner fiber wall thinkness than in the out of pore zone (latewood) in wood ring-porous species [27] could also affect the variation in shrinkage of the wood. Further experiments will be clearly needed to determine the variation in cell morphology as well as earlywood-latewood proportion from pith to bark in wood of M. azedarach.

Cutting wood log into thin disks is an advantageous to better understand the evolution of drying stresses because of the possibility to compare drying strains between tangential and radial directions [28]. Shrinkage ratio is an important parameter that can be used to characterize the performance of wood drying. The difference of the shrinkage between the tangential and radial shrinkage has been found to strongly affect the internal stress that occurs during drying [29]. Generally, the tangential shrinkage was assumed to be 1.5-2.5 times as large as the radial shrinkage for $M$. azedarach (Table 6). In this study, in radial direction, the $\alpha_{\mathrm{T}} / \alpha_{\mathrm{R}}$ decreased significantly from 10 to $50 \%$ of the radial length from pith before approaching a constant 
value toward the outside. The $\alpha_{\mathrm{T}} / \alpha_{\mathrm{R}}$ near the pith was 1.76 higher than that in middle and outer parts (respective values were 1.59 and 1.56) (Table 5). The difference in radial and tangential shrinkage is attributed to differences in density of earlywood and latewood. The shrinkage of dense latewood cells is greater than that of earlywood. In the radial direction, both the earlywood and latewood shrink independently and the total shrinkage corresponds roughly to the weighted mean shrinkage of the two components, whereas tangential shrinkage is largely controlled by the changes in latewood. In addition, Anagnost et al. [30] assumed that MFA in the radial walls is equal (in Acer saccharum and Prunus serotina species) to significantly larger (in Drimys winteri species) than in the tangential walls. This is because bordered pits in the radial walls force the microfibrils to deviate around them.

The results of ANOVA indicated that height level was not an important source of variation. Site was an important source $(p<0.05)$ of variation in $\alpha_{\mathrm{T}}, \alpha_{\mathrm{R}}$, and $\alpha_{\mathrm{T}} / \alpha_{\mathrm{R}}$ (Table 7). The $\alpha_{\mathrm{T}}$ and $\alpha_{\mathrm{R}}$ values in site 2 were larger than those in site 1 (Table 5). The variations in wood properties of the same species are due to different genotypes and growth conditions. Until now, there have been no reports of effect of these factors on transverse shrinkage in M. azedarach. However, the effects of seed source and growth condition on transverse shrinkage have been investigated in other hardwood species.
Montes et al. [31] found there was significant genetic variation in wood shrinkage of Calycophyllum spruceanum while Yang et al. [32] reported that site had a highly significant effect on shrinkage properties in Eucalyptus globulus Labill. Thus, the significant differences in transverse shrinkage between two sites in this study could be caused by the differences in growth conditions such as altitude, mean annual rainfall, and soil types between two sites (Table 1). In the future, the effect of seed source factor on wood shrinkages in $M$. azedarach is needed to clarify. The different results in wood transverse shrinkage of $M$. azedarach planted in different countries were also reported by other researchers (Table 6). This could be due to the forest sites in different studies. The difference in transverse shrinkage between sites suggests the amount of shrinkage, the drying stress, and the incidence of drying defects such as cracks or deformations might differ among lumber sawn from different sites.

\section{Relationships between transverse shrinkage and BD}

The degree of correlation between transverse shrinkage and BD was evaluated by liner regression analysis. The results are presented in Table 8 and Fig. 3. BD had significant positive linear correlations with $\alpha_{\mathrm{T}}$ and $\alpha_{\mathrm{R}}$ both in each site and combined sites at the 0.001 confidence level. For
Table 8 Relationship between transverse shrinkage and basic density (BD) for each site and combined sites of Melia azedarach

\begin{tabular}{|c|c|c|c|c|c|c|c|c|c|c|}
\hline \multirow[t]{3}{*}{ Variable } & \multirow{3}{*}{$n$} & \multicolumn{9}{|c|}{ Linear regression model $y=\mathrm{a} x+\mathrm{b}$} \\
\hline & & \multicolumn{3}{|l|}{$\alpha_{\mathrm{T}}$} & \multicolumn{3}{|l|}{$\alpha_{\mathrm{R}}$} & \multicolumn{3}{|l|}{$\alpha_{\mathrm{T}} / \alpha_{\mathrm{R}}$} \\
\hline & & $a$ & $b$ & $r$ & $a$ & $b$ & $r$ & $a$ & $b$ & $r$ \\
\hline Site 1 & 90 & 11.25 & 1.95 & $0.76^{* * * *}$ & 12.33 & -1.14 & $0.86^{* * *}$ & -2.57 & 2.77 & $-0.59^{* * *}$ \\
\hline Site 2 & 90 & 12.58 & 1.78 & $0.66^{* * *}$ & 13.10 & -1.16 & $0.76^{* * *}$ & -1.97 & 2.48 & $-0.40^{* * *}$ \\
\hline Combined sites & 180 & 12.63 & 1.56 & $0.72^{* * *}$ & 13.31 & -1.41 & $0.82^{* * *}$ & -2.43 & 2.69 & $-0.53^{* * *}$ \\
\hline
\end{tabular}

$n$ number of wood specimen

$\alpha_{\mathrm{T}}$ tangential shrinkage, $\alpha_{\mathrm{R}}$ radial shrinkage, $\alpha_{\mathrm{T}} / \alpha_{\mathrm{R}}$ tangential/radial shrinkage ratio, $r$ correlation coefficient

${ }^{* * *} p<0.001$
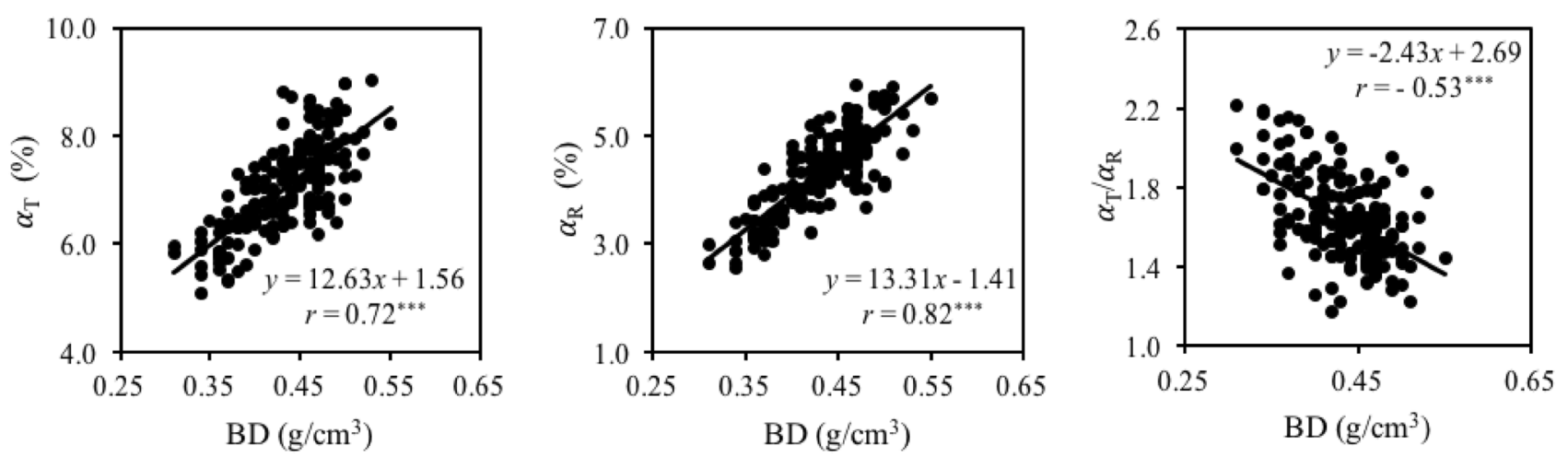

Fig. 3 Relationships between transverse shrinkage $\left(\alpha_{\mathrm{T}}, \alpha_{\mathrm{R}}\right.$, and $\left.\alpha_{\mathrm{T}} / \alpha_{\mathrm{R}}\right)$ and BD for combined sites of Melia azedarach (Triple asterisk: $p<0.001$ ) 
combined sites, the value of $r$ is 0.72 and 0.82 for $\alpha_{\mathrm{T}}$ and $\alpha_{\mathrm{R}}$, respectively. The $\alpha_{\mathrm{T}} / \alpha_{\mathrm{R}}$ was negatively correlated with $\mathrm{BD}$ $(r=-0.53, p<0.001)$, which was the inverse of the relationships for $\alpha_{\mathrm{T}}$ and $\alpha_{\mathrm{R}}$.

Density is widely acknowledged to reflect shrinkage property. Istikowati et al. [33] found strong positive correlations of BD with $\alpha_{\mathrm{T}}(r=0.83)$, and $\alpha_{\mathrm{R}}(r=0.83)$ in Artocarpus elasticus, Neolitse latifolia, and Alphitonia excelsa. Kord et al. [24], Wu et al. [34], Sadegh et al. [35], and Pliura et al. [36] also observed significant positive correlations between BD and both $\alpha_{\mathrm{T}}$ and $\alpha_{\mathrm{R}}$ in Populus euramericana, Eucalypt species, Tamarix aphylia, and Poplar hybrid crosses, respectively. The positive correlations between $\mathrm{BD}$ and both $\alpha_{\mathrm{T}}$ and $\alpha_{\mathrm{R}}$ suggest that selection for high wood density may lead to increased wood transverse shrinkage of $M$. azedarach planted in northern Vietnam.

\section{Prediction of transverse shrinkage}

The results of linear regression analysis for the transverse shrinkage $\left(\alpha_{\mathrm{T}}, \alpha_{\mathrm{R}}\right.$, and $\left.\alpha_{\mathrm{T}} / \alpha_{\mathrm{R}}\right)$ and $V_{\mathrm{L}}, \mathrm{DMOE}_{\mathrm{log}}$ in green condition are presented in Table 9 and Fig. 4 . The results showed that the $\alpha_{\mathrm{T}}$ and $\alpha_{\mathrm{R}}$ have positive relationships with $V_{\mathrm{L}}$ (respective $r$ values for $\alpha_{\mathrm{T}}$ and $\alpha_{\mathrm{R}}$ were 0.47 and 0.45 ). This indicates that acoustic wave measurement in green condition has a potential to be used as a non-destructive method for predicting the transverse shrinkage of M. azedarach planted in northern Vietnam. Dundar et al. reported that ultrasonic velocity was a significant predictor of transverse shrinkage by strong correlation between ultrasonic velocity and shrinkage on both hardwood (Quercus petraea Lieblein and Castanea sativa Mill.) [5] and softwood species (Picea sitchensis and Tsuga heterophylla) [10].

The correlation coefficients between $\mathrm{DMOE}_{\log }$ and transverse shrinkage (respective $r$ values for $\alpha_{\mathrm{T}}$ and $\alpha_{\mathrm{R}}$ were 0.62 and 0.59) (Table 9) were stronger than between $V_{\mathrm{L}}$ and transverse shrinkage. The coefficients of determination increased considerably in both $\alpha_{\mathrm{T}}$ and $\alpha_{\mathrm{R}}$ when the acoustic wave velocity and green density of $\log (\rho)$ were used together to

Table 9 The coefficients of correlation $(r)$ and coefficients of determination $\left(R^{2}\right)$ between transverse shrinkage $\left(\alpha_{\mathrm{T}}, \alpha_{\mathrm{R}}\right.$, and $\left.\alpha_{\mathrm{T}} / \alpha_{\mathrm{R}}\right)$ and acoustic wave velocity $\left(V_{\mathrm{L}}\right)$, dynamic modulus of elasticity of $\log$ $\left(\mathrm{DMOE}_{\log }\right)$ for the combined sites

\begin{tabular}{|c|c|c|c|c|}
\hline \multirow[t]{2}{*}{ Shrinkage } & \multicolumn{2}{|l|}{$V_{\mathrm{L}}$} & \multicolumn{2}{|l|}{ DMOE $_{\log }$} \\
\hline & $r$ & $R^{2}$ & $r$ & $R^{2}$ \\
\hline$\alpha_{\mathrm{T}}$ & $0.47^{* *}$ & 0.218 & $0.62^{* * *}$ & 0.391 \\
\hline$\alpha_{\mathrm{R}}$ & $0.45^{*}$ & 0.199 & $0.59^{* * * *}$ & 0.343 \\
\hline$\alpha_{\mathrm{T}} / \alpha_{\mathrm{R}}$ & $-0.15^{\mathrm{ns}}$ & 0.021 & $-0.14^{\mathrm{ns}}$ & 0.018 \\
\hline
\end{tabular}

$n s$ no significant

${ }^{* * *} p<0.001,{ }^{* *} p<0.01,{ }^{*} p<0.05$ predict shrinkage. For example, the $V_{\mathrm{L}}$ explained $21.8 \%$ for $\alpha_{\mathrm{T}}$ and $19.9 \%$ for $\alpha_{\mathrm{R}}$ alone, it was raised to $39.1 \%$ for $\alpha_{\mathrm{T}}$ and $34.3 \%$ for $\alpha_{\mathrm{R}}$ (Table 9) when $V_{\mathrm{L}}$ and $\rho$ were used together. This implies that the better prediction of the transverse shrinkage can be achieved when both $V_{\mathrm{L}}$ and $\rho$ are used as predicting parameters through calculation of $\mathrm{DMOE}_{\text {log }}$ in green condition. The $\alpha_{\mathrm{T}} / \alpha_{\mathrm{R}}$ was negatively correlated with both $V_{\mathrm{L}}$ and $\mathrm{DMOE}_{\mathrm{log}}$ and no significance (Table 9). Yamashita et al. [8] also showed that $\mathrm{DMOE}_{\log }$ in the green condition has significant relationships with transverse shrinkage and it might be possible to sort lumber with large transverse shrinkage by measuring the modulus of elasticity in Cryptomeria japonica. Dundar et al. [5] reported that the prediction of the transverse shrinkage is better when both ultrasonic velocity and specific gravity are used together for Quercus petraea Lieblein and Castanea sativa Mill.

\section{Grade yield of shrinkage properties}

Figure 5 shows the grade yield for both $\alpha_{\mathrm{T}}$ and $\alpha_{\mathrm{R}}$ using grading standard of physical properties of timbers from Southeast Asia and Pacific regions by FFPRI [18]. The grade yield for $\alpha_{\mathrm{T}}$ in site 1 was the highest for grade II with $68 \%$, followed by grade I and III with 28 and 4\%, respectively. The highest frequency of specimens for $\alpha_{\mathrm{T}}$ in site 2 also belonged to grade II with $78 \%$, followed by grade III and I with 17 and 6\%, respectively. There was no grade yield of $\alpha_{\mathrm{T}}$ in grades IV and $\mathrm{V}$ for both sites. The highest frequency of specimens for $\alpha_{\mathrm{R}}$ in both sites can be allocated mainly in to grade III (respective frequency for site 1 and site 2 were 62 and 59\%). Based on results in Table 5 and Fig. 5, wood of $M$. azedarach planted in northern Vietnam can be allocated into grade II for tangential shrinkage property and grade III for radial shrinkage property using grading standard of physical properties of timbers from Southeast Asia and Pacific regions. These results should provide useful information to assess the wood quality of this species and for wood processors in wood drying and furniture industry as well as for the sustainable wood utilization of the $M$. azedarach trees planted in northern Vietnam.

\section{Conclusions}

The results of this study indicated that radial position had significant $(p<0.001)$ effect on shrinkage variations. The variation pattern in $\alpha_{\mathrm{T}}$ and $\alpha_{\mathrm{R}}$ was found to increase gradually from pith to bark and this trend was similar on both sites. In radial direction, the $\alpha_{\mathrm{T}} / \alpha_{\mathrm{R}}$ decreased significantly from 10 to $50 \%$ of the radial length from pith before approaching a constant value toward the outside. The transverse shrinkage variation with height was very small and without statistical significant. The strong 

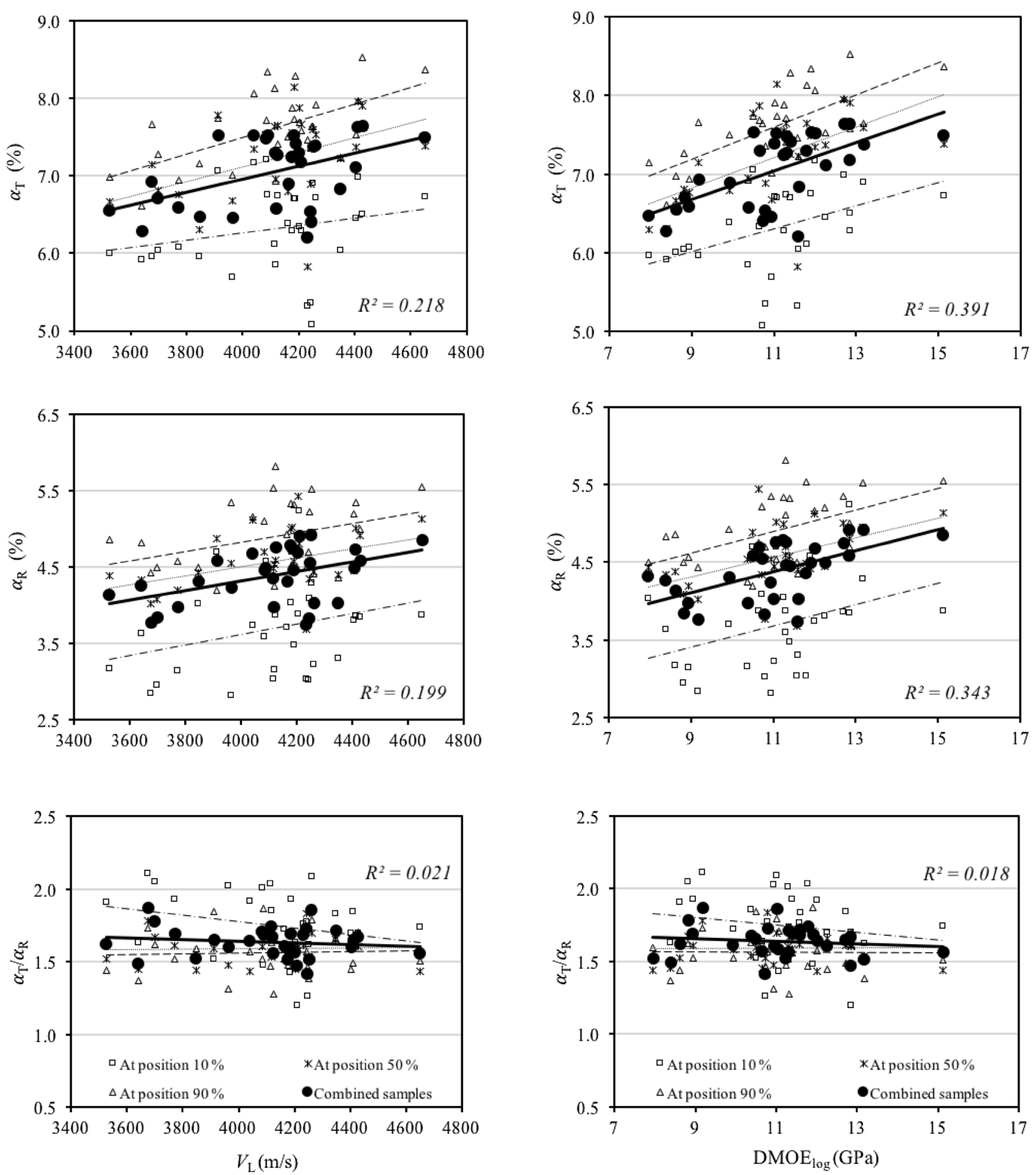

Fig. 4 Relationships between transverse shrinkage $\left(\alpha_{\mathrm{T}}, \alpha_{\mathrm{R}}\right.$, and $\left.\alpha_{\mathrm{T}} / \alpha_{\mathrm{R}}\right)$ and acoustic wave velocity $\left(V_{\mathrm{L}}\right)$; transverse shrinkage and dynamic modulus of elasticity of $\log \left(\mathrm{DMOE}_{\mathrm{log}}\right)$ for combined sites of Melia azedarach. Long dash dot, round dot, and long dash lines

are relationships at 10,50 , and $90 \%$ of the radial position from pith, respectively. Thick solid lines together with coefficients of determination $\left(R^{2}\right)$ is relationship for combined samples of three positions

relationship between BD and transverse shrinkage suggests that BD was a good predictor of dimensional stability. Both $\alpha_{\mathrm{T}}$ and $\alpha_{\mathrm{R}}$ had positive relationships with $V_{\mathrm{L}}$ and

$\mathrm{DMOE}_{\text {log }}$. The better results for prediction of shrinkage of $M$. azedarach were obtained when $V_{\mathrm{L}}$ and $\rho$ were used together through calculation of $\mathrm{DMOE}_{\text {log }}$. This shows that 

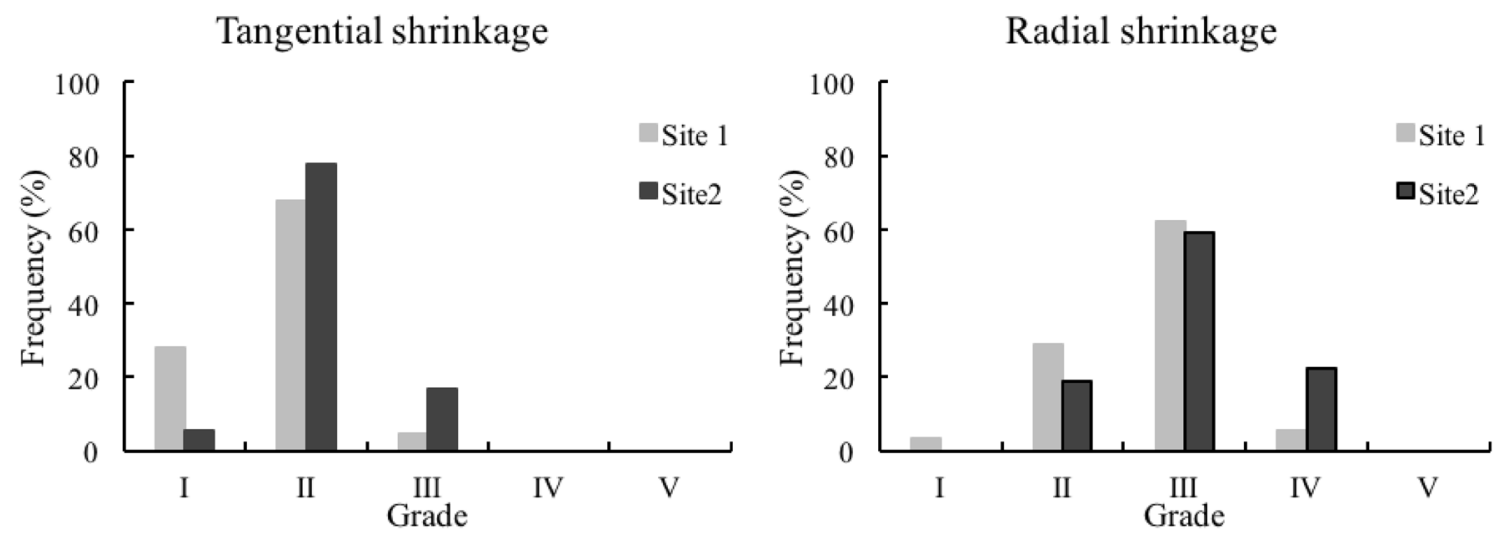

Fig. 5 Specimen grade allocation in terms of tangential shrinkage $\left(\alpha_{\mathrm{T}}\right)$ and radial shrinkage $\left(\alpha_{\mathrm{R}}\right)$ for both sites according to grading standard of physical properties of timbers from Southeast Asia and Pacific regions by FFPRI [18]

acoustic wave measurement in green condition has a good potential for predicting the transverse shrinkages of $M$. azedarach planted in northern Vietnam. The results of this study, therefore, provide a basis for sorting lumbers with large shrinkage during drying in $M$. azedarach by stress wave method. Besides, wood of $M$. azedarach planted in northern Vietnam can be allocated into grade II for tangential shrinkage property and grade III for radial shrinkage property using grading standard of physical properties of timbers from Southeast Asia and Pacific regions.

Acknowledgements The first author was funded by Vietnam government for a Doctor course at Graduate School of Bioresource and Bioenvironmental Sciences, Kyushu University, Fukuoka, Japan.

\section{Compliance with ethical standards}

Conflict of interest The authors declare no conflict of interest.

\section{References}

1. Zobel BJ, Van Buijtenen JP (1989) Wood variation, its causes and control. Springer, Heidelberg

2. Koga S, Zang SY (2004) Inter-tree and intra-tree variations in ring width and wood density components in balsam fir (Abies balsamea). Wood Sci Technol 38:149-162

3. Wang E, Chen T, Pang S, Karalus A (2008) Variation in anisotropic shrinkage of plantation grown Pinus radiata wood. Maderas. Ciencia y tecnologia 10:243-249

4. Forest Products Laboratory (2010) Wood handbook-wood as an engineering material. General technical report FPL-GTR-190. United States Department of Agriculture Forest Service. Madison

5. Dundar T, Wang X, As N, Avci E (2016) Potential of ultrasonic pulse velocity for evaluating the dimensional stability of oak and chestnut wood. Ultrasonics 66:86-90

6. Skaar C (1988) Wood-water relations. Springer, Berlin Heidelberg, pp 122-176
7. Yamashita K, Hirakawa Y, Nakatani H, Ikeda M (2009) Longitudinal shrinkage variations within trees of sugi (Cryptomeria japonica) cultivars. J Wood Sci 55:1-7

8. Yamashita K, Hirakawa Y, Nakatani H, Ikeda M (2009) Tangential and radial shrinkage variation within trees in sugi (Cryptomeria japonica) cultivars. J Wood Sci 55:161-168

9. Wang X, Simpson WT (2006) Using acoustic analysis to presort warp-prone ponderosa pine 2 by $4 \mathrm{~s}$ before kiln-drying. Wood Fiber Sci 38:206-214

10. Dundar T, Wang X, Ross RJ (2013) Prediction of transverse shrinkages of young-growth Sitka spruce (Picea sitchensis) and western hemlock (Tsuga heterophylla) with ultrasonic measurements. Wood Mat Sci Eng 8:234-241

11. EL-Juhany LI (2011) Evaluation of some wood quality measures of eight-year-old Melia azedarach trees. Turk J Agric For $35: 165-171$

12. Harrison NA, Boa E, Carpio ML (2003) Characterization of phytoplasmas detected in Chinaberry trees with symptoms of leaf yellowing and decline in Bolivia. Plant Pathol 52:147-157

13. Orwa C, Jamnadass RH, Kindt R, Mutua A, Simons A (2009) Agroforestree database: a tree species reference and selection guide version 4.0. http://www.worldagroforestry.org. Accessed 10 Sept 2017

14. Nghia NH (2007) Atlas of Vietnam's forest tree species. Agric Publ House 1:242

15. Duong DV, Missanjo E, Matsumura J (2017) Variation in intrinsic wood properties of Melia azedarach L. planted in northern Vietnam. J Wood Sci 63:560-567

16. JIS Z2101-1994 (2000) Methods of test for woods (in Japanese). Japanese Standard Association, Tokyo

17. R-software and all packages used are available from CRAN at https://cran.r-project.org. Accessed 07 Aug 2017

18. Forestry and Forest Products Research Institute (1975) The properties of tropical woods 21: evaluation of wood properties and wood processing suitabilities of timber from Southeast Asia and the Pacific regions. Bull Gov For Exp Station 277:87-130

19. Pramana GSJ (1998) Holzeigenschaften und Verwendungsmöglichkeiten von Melia azedarach L. aus forstlichem Anbau auf Java (in German). Dissertation, Universität Göttingen. Cuvillier XXI, Göttingen

20. Venson I, Guzman JAS, Talavera FJF, Richter HG (2008) Biological, physical and mechanical wood properties of Paraiso (Melia azedarach) from a roadside planting at Huaxtla, Jalisco, Mexico. J Trop For Sci 20:38-47 
21. Botero FA (1956) Métodos de ensaios adotados no IPT para o estudo de madeiras nacionais. In: Tabelas e resultados obtidos para madeiras nacionais (in Spanish). Instituto de Pesquisas Tecnologicas, São Paul, Boletim No. 131

22. Coronel EO (1989) Estudio y determinación de las propiedades físico-mecánicas de las maderas del Parque Chaqueño. Valores y variaciones, 1a Parte (in Spanish). Universidad Nacional de Santiago del Estero, Serie de Publicaciones No. 8906

23. Ofori J, Brentuo B (2005) Green moisture content, basic density, shrinkage and drying characteristics of the wood of Cedrela odorata grown in Ghana. J Trop For Sci 17:211-223

24. Kord B, Kialashaki A, Kord B (2010) The within-tree variation in wood density and shrinkage, and their relationship in Populus euramericana. Turk J Agric For 34:121-126

25. Anoop EV, Jijeesh CM, Sindhumathi CR, Jayasree CE (2014) Wood physical, anatomical and mechanical properties of big leaf Mahogany (Swietenia macrophylla Roxb) a potential exotic for south India. Res J Agric For Sci 2:7-13

26. Shanavas A, Kumar BM (2006) Physical and mechanical properties of three agroforestry tree species from Kerala, India. J Trop Agric 44:23-30

27. IAWA Committee (1989) IAWA list of microscopic features for hardwood identification. IAWA J 10:219-332

28. Fu Z, Zhao J, Yang Y, Cai Y (2016) Variation of drying strains between tangential and radial directions in Asian white birch. Forests 7:59

29. Dahlblom O, Petersson H, Ormarsson S (1999) Characterization of shrinkage. European project FAIR CT 96-1915, improved
Spruce timber utilization. Division of Structural Mechanics, Lund Institute of Technology, Lund University, Scania

30. Anagnost SE, Mark RE, Hanna RB (2005) $S_{2}$ orientation of microfibrils in softwood tracheids and hardwood fibers. IAWA J 26:325-338

31. Montes CS, Beaulieu J, Hernander RE (2007) Genetic variation in wood shrinkage and its correlations with tree growth and wood density of Calycophyllum spruceanum at an early wood in the Peruvian Amazon. Can J For Res 37:966-976

32. Yang JL, Fife D, Ilic J, Blackwell P (2002) Between-site and between-provenance differences in shrinkage properties of 10-year-old Eucalyptus globulus Labill. Aust For 65:220-226

33. Istikowati WT, Ishiguri F, Aiso H, Hidayati F, Tanabe J, Iizuka K, Sutiya B, Wahiudy I, Yokota S (2014) Physical and mechanical properties of woods from three native fast-growing species in a secondary forest in south Kalimantan, Indonesia. For Prod J 64:48-54

34. Wu YQ, Hayashi K, Liu Y, Cai Y, Sugimori M (2006) Relationships of anatomical characteristics versus shrinkage and collapse properties in plantation-grown eucalypt wood from China. J Wood Sci 52:187-194

35. Sadegh AN, Kiaei M, Samariha A (2012) Experimental characterization of shrinkage and density of Tamarix aphylla wood. Cellulose Chem Technol 46:369-373

36. Pliura A, Yu Q, Zhang SY, Mackay J, Perinet P, Bousquet J (2005) Variation in wood density and shrinkage and their relationship to growth of selected young poplar hybrid crosses. For Sci 51:472-482 